\title{
EXTRA-ANATOMIC AORTIC BYPASS VIA STERNOTOMY FOR COMPLEX AORTIC ARCH STENOSIS IN CHILDREN
}

Kirk R. Kanter, MD

Eldad Erez, MD

Willis H. Williams, MD

Vincent K. H. Tam, MD
Objective: Recurrent aortic narrowing after repair of aortic coarctation or interrupted aortic arch, as well as diffuse, long-segment aortic hypoplasia, can be difficult to manage. Extra-anatomic ascending aorta-descending aorta bypass grafting through a sternotomy is an alternative approach for this problem.

Methods: Since 1985, 19 patients aged 2 months to 18 years (mean 10.7 years) underwent extra-anatomic bypass with 10- to 30-mm Dacron grafts. The initial diagnosis was coarctation with hypoplastic arch in 15, interrupted aortic arch in 3, and diffuse long-segment aortic hypoplasia in 1 . Seventeen of the children had a total of 22 previous operations: transthoracic interposition or bypass graft $(n=7)$, end-to-end anastomosis $(n=7)$, subclavian arterioplasty $(n=6)$, and synthetic patch $(n=2)$. The mean time from initial repair was 8.0 years (range $0.6-18$ years). Three children had previous sternotomies. Cardiopulmonary bypass was avoided in all but 6 patients ( 5 with simultaneous intracardiac repairs).

Results: No hospital or late deaths occurred. On follow-up from 4 months to 14.7 years (mean 7.9 years), no reoperations for recurrent stenosis were performed. Two patients have arm-to-leg pressure gradients: $20 \mathrm{~mm} \mathrm{Hg}$ at rest in 1 patient and a $60-\mathrm{mm} \mathrm{Hg}$ systolic exercise gradient with no resting gradient in the other. One patient required exclusion of an aortic aneurysm at the old coarctation repair site 13 years after extra-anatomic bypass. Three children had subsequent successful cardiac operations.

Conclusions: Extra-anatomic bypass is an effective and relatively easy approach for selected cases of complex or reoperative aortic arch obstruction. It should be considered as an alternative operative technique for complex aortic arch reconstruction. (J Thorac Cardiovasc Surg 2000;120:885-90)
$\mathrm{R}$ ecurrent aortic narrowing after repair of aortic coarctation or interrupted aortic arch, as well as diffuse, long-segment aortic hypoplasia, can be difficult to manage. Various approaches have been proposed for

From the Division of Cardio-Thoracic Surgery, Department of Surgery, Emory University School of Medicine, Atlanta, Ga.

Read at the Eightieth Annual Meeting of The American Association for Thoracic Surgery, Toronto, Ontario, Canada, April 30-May 3, 2000.

Received for publication May 3, 2000; accepted for publication July 25, 2000.

Address for reprints: Kirk R. Kanter, MD, Division of CardioThoracic Surgery, Emory University School of Medicine, 1365 Clifton Rd, Atlanta, GA 30322 (E-mail: kkanter@emory.org).

Copyright (C) 2000 by The American Association for Thoracic Surgery

$0022-5223 / 2000 \$ 12.00+0 \quad \mathbf{1 2 / 6 / 1 1 0 4 6 2}$

doi: $10.1067 / \mathrm{mtc} .2000 .110462$ this group of problems, including percutaneous balloon dilatation with or without stenting, resection of the narrowed segment with direct reanastomosis, or patch aortoplasty. In addition, others have proposed the use of tube grafts as interposition grafts, bypass grafts from the aortic arch or subclavian artery to the descending aorta ("bucket-handle" graft), or extra-anatomic grafts from the ascending aorta to the descending aorta. Since 1985, we have selectively applied the technique of extra-anatomic bypass grafting from the ascending aorta to the descending aorta through a sternotomy; this experience forms the basis of this report.

\section{Patients and methods}

Patients. From 1985 to 1999 , a total of 19 children, aged 2 months to 18 years (mean 10.7 years) had an extra-anatomic bypass graft for complex aortic obstruction. The initial aortic 


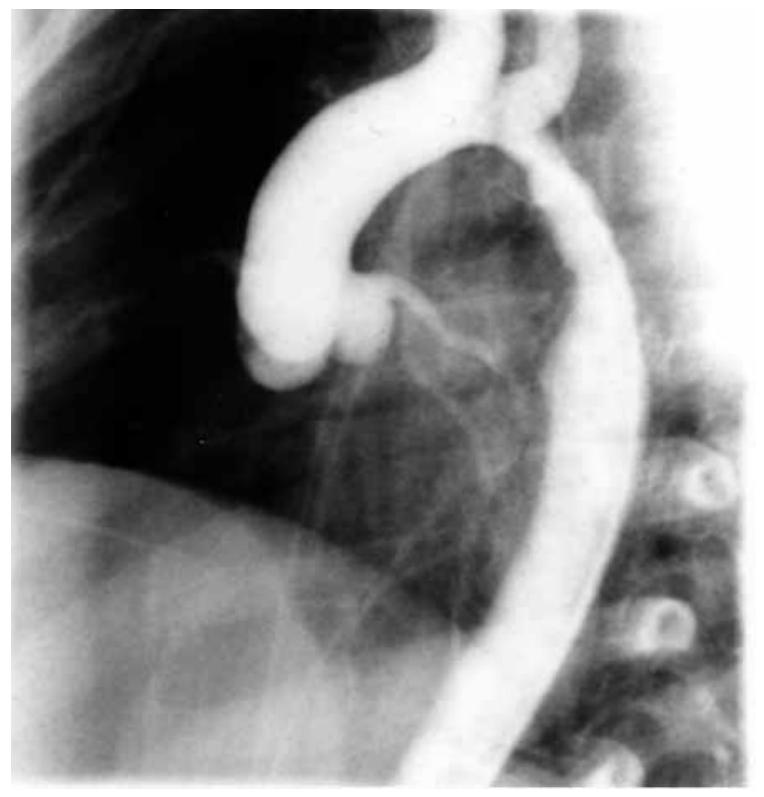

Fig 1. Lateral aortogram of a 7-year-old girl who underwent repair of a maximal coarctation (no communication between the transverse aorta and descending aorta) and hypoplastic aortic arch at 1 month of age. The initial repair involved pericardial patch enlargement of the hypoplastic transverse aorta and resection of the coarctation with end-to-end anastomosis augmented with a left subclavian flap aortoplasty. Recoarctation developed and responded to balloon dilatation when she was $2 \frac{1}{2}$ years of age. A recurrent long-segment recoarctation developed distal to the left carotid artery, as shown on this aortogram. Note that the left subclavian artery has been used to augment the transverse aorta.

problem was coarctation with hypoplastic aortic arch in 15 patients, interrupted aortic arch in 3 , and diffuse aortic hypoplasia in 1 .

Seventeen (89\%) of the 19 children had a total of 22 previous aortic operations: 7 transthoracic bypass grafts, 7 resections with end-to-end anastomosis, 6 subclavian flap aortoplasties, and 2 patch grafts. The interval from the initial aortic procedure to the extra-anatomic bypass graft ranged from 7 months to 18 years (mean $8.0 \pm 5.4$ years).

Three patients had a total of 4 previous cardiac operations: ventricular septal defect (VSD) closure and removal of a pulmonary artery band in 1 child, VSD closure and resection of subaortic stenosis in the second child, and VSD closure followed by subaortic stenosis resection during a separate operation in the third child. An aortogram from a representative case is shown in Fig 1.

Operative technique. Operative exposure is obtained through a standard median sternotomy (3 patients had a secondary sternotomy due to prior heart surgery). The right ventricle is retracted superiorly with pledget-supported stay sutures and the posterior pericardium is incised longitudinally to obtain exposure to the descending thoracic aorta above

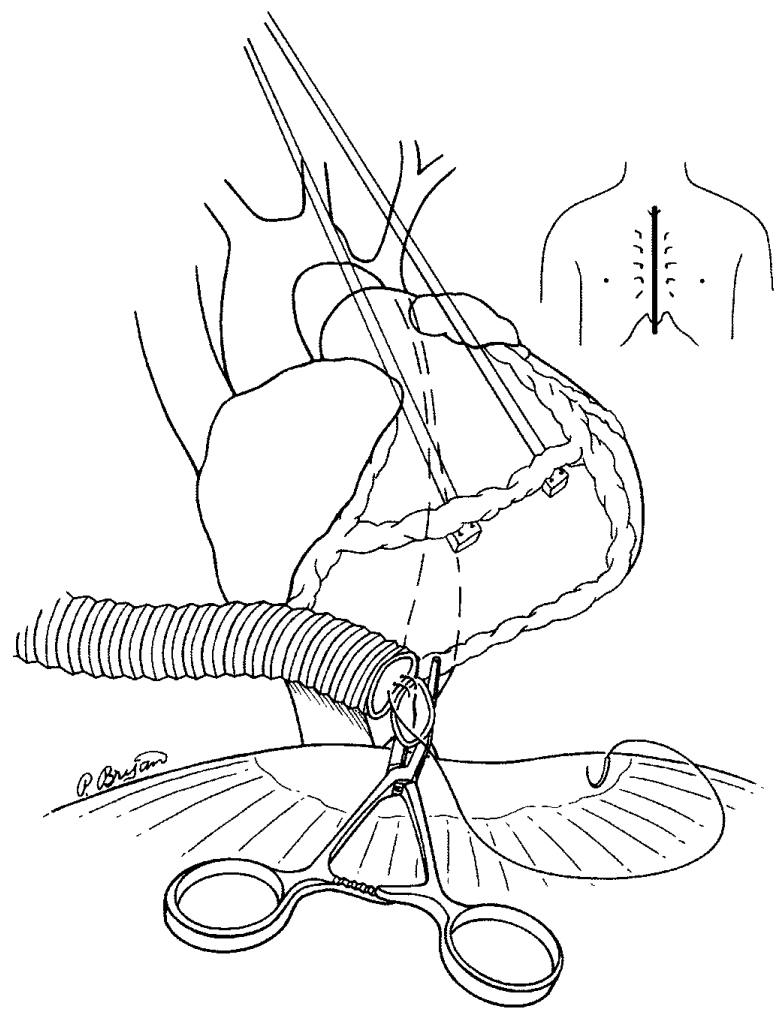

Fig 2. Operative technique. After sternotomy, the right ventricle is retracted superiorly and the descending aorta is encircled through an incision in the posterior pericardium. After partial heparinization, the distal Dacron graft anastomosis is performed with the aid of a partial occlusion clamp.

the diaphragm. The descending thoracic aorta is encircled for safety. After heparinization (100 U/kg), a partial occlusion clamp is applied and a large Dacron graft is anastomosed end to side to the descending aorta with continuous polypropylene suture (Fig 2). The sizes of the grafts ranged from 10 to $30 \mathrm{~mm}$ (median $20 \mathrm{~mm}$ ).

After hemostasis has been achieved, the heart is returned to its anatomic position, the graft is de-aired, and a generous loop is created in the pericardial cavity anterior to the inferior and superior venae cavae and lateral to the right atrium. Again, with the use of a partial occlusion clamp and continuous polypropylene suture, the proximal anastomosis is constructed on the right lateral aspect of the ascending aorta with sufficient redundancy in the graft to allow for growth (Fig 3). Finally, a right pleuropericardial flap is tacked anterior to the graft to protect it during any potential subsequent sternal re-entry.

Cardiopulmonary bypass (CPB) was not used in 13 (68\%) of the patients. Of the remaining 6 children, 5 had concomitant cardiac surgery. This involved VSD closure and removal of a pulmonary artery band in 2, aortic valvotomy in 1 , subaortic resection in 1, and repair of a partial atrioventricular septal defect in 1. CPB was used in only 1 child in whom simultaneous cardiac surgery was not performed. 
Fig 4, $A$, shows a frame from the preoperative angiogram of a 2-month-old child with a partial atrioventricular septal defect, pulmonary hypertension, a small left ventricle, and a diffusely hypoplastic transverse aorta and descending aorta with a 41-mm $\mathrm{Hg}$ systolic gradient from the left ventricle to the femoral artery. He underwent repair of the partial atrioventricular septal defect with placement of a 10-mm Dacron graft from the ascending aorta to the descending aorta above the diaphragm. Fig 4, $B$, shows a frame from a postoperative aortogram in the same patient, demonstrating the widely patent bypass graft and the diminutive native descending aorta.

\section{Results}

No hospital or late deaths occurred. On follow-up from 4 months to 14.7 years (mean $7.9 \pm 5.0$ years), there have been no reinterventions for recurrent stenosis. One patient has mild systolic systemic hypertension. Two patients have arm-to-leg blood pressure gradients: $20 \mathrm{~mm} \mathrm{Hg}$ (11-mm $\mathrm{Hg}$ mean gradient by Doppler echocardiography) at rest in 1 patient and a 60-mm Hg systolic exercise gradient with no resting gradient in the other.

Four subsequent successful cardiac operations have been performed in 3 children. One child had combined mitral valve replacement and aortic valve replacement by means of a Konno aortoventriculoplasty 11 months after the aortic bypass graft. One child had closure of a residual VSD 9.7 months after the bypass graft and concomitant VSD closure. The third child had a composite aortic root replacement 4.9 years after the aortic bypass graft followed 2.2 years later by repair of prosthetic aortic valve insufficiency.

Only one subsequent aortic operation has been necessary in this series. This patient underwent primary repair of a tight, long-segment coarctation at 10.6 years of age; a 16-mm Dacron graft was inserted from the transverse aortic arch to the descending aorta through a left thoracotomy ("bucket-handle" graft). At 14.5 years of age, because of a persistent transverse aortic arch obstruction between the innominate artery and the left carotid artery, a 22-mm Dacron graft was constructed between the ascending aorta and descending aorta through a sternotomy. Although this graft successfully relieved the arch obstruction, 13.2 years later a large aneurysm developed at the proximal suture line of the bucket-handle graft near the original coarctation site. Since the extra-anatomic bypass graft from the ascending aorta to the descending aorta was widely patent, it was a relatively simple matter to exclude the aneurysm through a secondary thoracotomy without significant concern about spinal cord ischemia or renal perfusion.

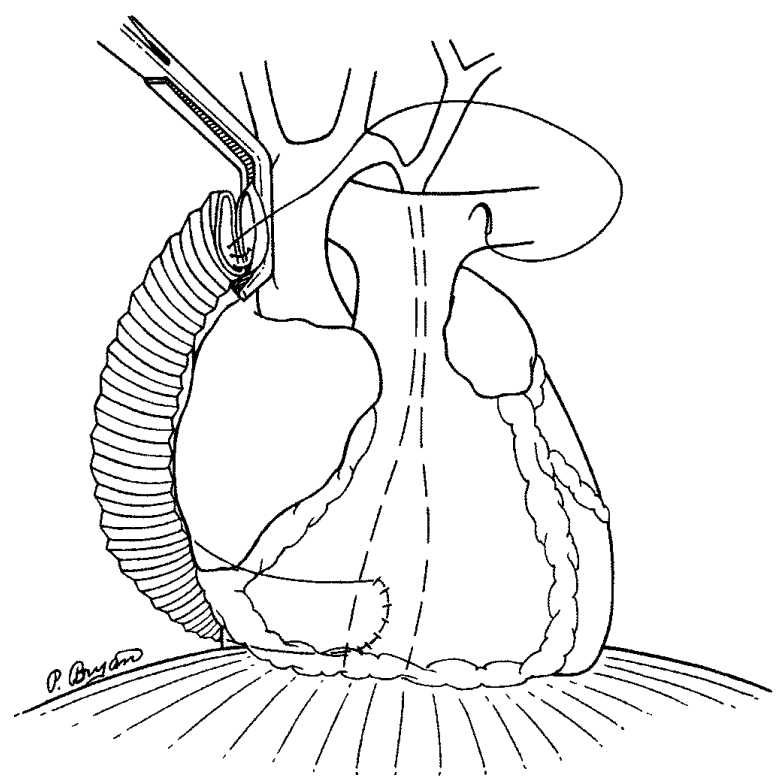

Fig 3. Operative technique (continued). The Dacron graft is brought lateral to the right atrium and anterior to the inferior and superior venae cavae. The proximal graft anastomosis is constructed on the ascending aorta with the aid of a partial occlusion clamp.

\section{Discussion}

Bypass grafts for relief of primary or recurrent aortic arch obstruction have been used with a variety of techniques. In 1973, Weldon and associates ${ }^{1}$ described the construction of a tube graft from the transverse aorta to the descending aorta through a redo thoracotomy to bypass a recurrent coarctation in 4 children (the bucket-handle graft). This technique has been widely applied with good results, ${ }^{2,3}$ although it does not adequately address the problem of narrowing of the proximal aortic $\operatorname{arch}^{4}$ and it still requires a redo left thoracotomy.

In 1974, Siderys and coworkers ${ }^{5}$ reported the case of a 46-year-old woman with coarctation and a dense left fibrothorax due to tuberculosis. They fashioned a tube graft from the ascending aorta to the infrarenal descending aorta through a combined median sternotomy and laparotomy incision, successfully bypassing the coarctation segment. This technique of ascending aorta-infrarenal abdominal aorta bypass has been applied to a variety of aortic problems ${ }^{6-8}$ and has even been performed in conjunction with aortic root replacement in the face of interrupted aortic arch in the adult. ${ }^{9}$ Disadvantages of this technique are related to the long graft necessary to reach the infrarenal abdominal aorta and the need for an additional laparotomy incision. 

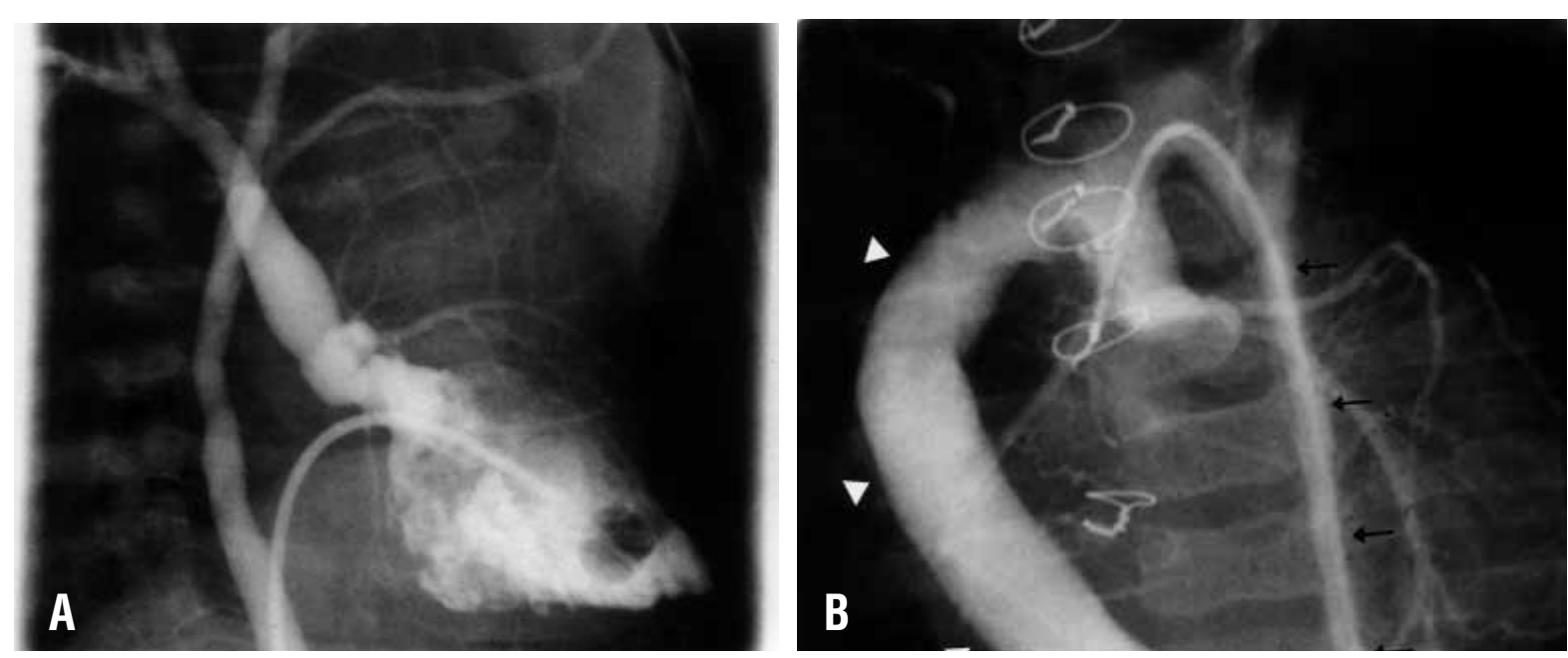

Fig 4. A, Right anterior oblique left ventriculogram of a 2-month-old child with a partial atrioventricular septal defect showing a diffusely hypoplastic transverse and descending aorta. B, Postoperative anteroposterior aortogram showing a widely patent bypass graft (white arrowheads) and an extremely diminutive native descending aorta (black arrows) traversed by the angiography catheter.

A variation of the ascending aorta-infrarenal abdominal aorta bypass graft was described by Wukasch and colleagues ${ }^{10}$ in 9 patients in whom the distal anastomosis was made to the supraceliac abdominal aorta. This procedure has not been adopted widely ${ }^{11-13}$ and also has the disadvantage of needing an additional laparotomy.

This current series outlines our results with extraanatomic bypass grafting from the ascending aorta to the descending aorta solely through a sternotomy incision for complex aortic problems. A modification of this technique was first described by Edie and coworkers $^{2}$ in 4 patients with recurrent coarctation. However, their method used a separate left thoracotomy for the distal aortic anastomosis followed by a sternotomy for the proximal anastomosis. The graft was routed anterior to the hilum of the left lung to the left lateral aspect of the ascending aorta. The late results in children treated with this technique have been good. ${ }^{14}$

Vijayanagar and colleagues ${ }^{15}$ were the first to describe performing the ascending aorta-descending aorta bypass entirely through a sternotomy incision. However, they brought the distal graft anterior and to the left of the heart, anastomosing it to the descending aorta through the left pleural space, while the patient was being supported with CPB for a concomitant aortic valve replacement. Similarly, Barron and associates, ${ }^{16}$ at the time of intracardiac repair on CPB, constructed an ascending aorta-descending aorta bypass graft for recurrent coarctation in 2 children; they also used a different method of routing the distal conduit from that used by us.
Powell, Adams, and Cooley ${ }^{17}$ first described the exact technique for ascending-descending bypass grafting used in our series in 4 adults aged 19 to 70 years undergoing simultaneous valvular heart surgery. This strategy of bypassing the coarctation with an extraanatomic ascending-descending graft at the time of repair of heart defects with CPB has been used by others, ${ }^{18,19}$ as well as in 5 patients in our series.

In patients who have isolated complex aortic obstruction or recurrent coarctation without defects requiring simultaneous cardiac repair, the extra-anatomic bypass graft can be constructed with the aid of CPB as described by Heinemann and associates ${ }^{12}$ and used in 1 patient in our series. In the majority of cases, however, this graft can be placed without the use of CPB as described by Sweeney, ${ }^{3}$ Grinda, ${ }^{4}$ and their colleagues and as was done in 13 of our patients.

An alternative approach to extra-anatomic bypass grafting from the ascending aorta to the descending aorta for aortic arch problems can be achieved through a right thoracotomy. ${ }^{20-24}$ Although this approach was not used in our series, it too has the advantages of avoiding a redo left thoracotomy, good access to the aorta well proximal and well distal to the diseased aortic segment, and ease of performance without the aid of CPB. Naturally, for simultaneous intracardiac repair, the right thoracotomy approach is less attractive than a sternotomy incision.

In summary, in this series of 19 children with complex aortic obstruction, we have found extra-anatomic bypass grafting from the ascending aorta to the 
descending aorta through a sternotomy to be a relatively simple, safe, and effective solution, with no mortality and no need for reintervention on follow-up. Concerns about spinal cord ischemia and renal perfusion, particularly in the face of absent or underdeveloped collateral arterial supply to the distal aorta, are very much minimized with this technique. Furthermore, the phrenic and recurrent laryngeal nerves are not placed in jeopardy as they would be with a redo left thoracotomy. Although concomitant cardiac repair can be accomplished during this same operation, as was done in 5 patients, we have found that CPB was typically unnecessary for isolated aortic problems. Also, if the graft is protected with a pleuropericardial pedicle, subsequent cardiac operations through a sternotomy can be performed quite safely, as was done in 4 instances in this series.

Finally, we must stress that this surgical technique is not our first choice for recurrent aortic obstruction. Techniques of percutaneous balloon dilatation for recurrent arch obstruction have yielded excellent results $^{25}$ and are currently our first treatment option (if feasible). In those patients requiring reoperation, we still prefer to avoid the use of bypass grafts. We prefer resection of the affected area with primary anastomosis or even patch aortoplasty. ${ }^{26}$ It is only in selected patients that we apply this technique of extra-anatomic bypass-patients with complex aortic obstruction or hypoplasia in whom other more traditional techniques seem less likely to succeed, those with underdeveloped collateral vessels, or those who need concomitant cardiac repair. In these patients, the technique used in this series is a valuable addition to the surgical repertoire for the management of complex aortic problems.

\section{REFERENCES}

1. Weldon CS, Hartmann AF Jr, Steinhoff NG, Morrissey JD. A simple, safe, and rapid technique for the management of recurrent coarctation of the aorta. Ann Thorac Surg 1973;15:510-9.

2. Edie RN, Janani J, Attai LA, Malm JR, Robinson G. Bypass grafts for recurrent or complex coarctations of the aorta. Ann Thorac Surg 1975;20:558-66.

3. Sweeney MS, Walker WE, Duncan JM, Hallman GL, Livesay JJ, Cooley DA. Reoperation for aortic coarctation: techniques, results, and indications for various approaches. Ann Thorac Surg 1985;40:46-9.

4. Grinda J, Macé L, Dervanian P, Folliguet TA, Neveux J. Bypass graft for complex forms of isthmic aortic coarctation in adults. Ann Thorac Surg 1995;60:1299-302.

5. Siderys H, Graffis R, Halbrook H, Kasbeckar V. A technique for management of inaccessible coarctation of the aorta. J Thorac Cardiovasc Surg 1974;67:568-70.

6. Gelfand ET, Callaghan JC, Sterns LP. Extended aortic bypass. J Thorac Cardiovasc Surg 1980;79:381-7.
7. Robicsek F, Hess PJ, Vajtai P. Ascending-distal abdominal aorta bypass for treatment of hypoplastic aortic arch and atypical coarctation in the adult. Ann Thorac Surg 1984;37:261-3.

8. Robicsek F. "Very long" aortic grafts. Eur J Cardiothorac Surg 1992;6:536-541.

9. Burton BJL, Kallis P, Bishop C, Swanton RH, Pattison CW. Aortic root replacement and extraanatomic bypass for interrupted aortic arch in an adult. Ann Thorac Surg 1995;60:1400-2.

10. Wukasch DC, Cooley DA, Sandiford FM, Nappi G, Reul GJ Jr. Ascending aorta-abdominal aorta bypass: indications, technique, and report of 12 patients. Ann Thorac Surg 1977;23:442-8.

11. Di Eusanio G, Astolfi D, Piccoli GP, Clementi G, Palminiello A. Diffuse hypoplasia of the thoracic aorta: surgical treatment with ascending aorta-supracaeliac abdominal aorta bypass graft. J Cardiovasc Surg 1982;23:344-7.

12. Heinemann MK, Ziemer G, Wahlers T, Köhler A, Borst HG. Extraanatomic thoracic aortic bypass grafts: indications, techniques, and results. Eur J Cardiothorac Surg 1997;11:169-75.

13. Nakamichi T, Katogi T, Ueda T, Aeba R, Yasudo M, Cho Y, et al. Extra-anatomic bypass from the ascending aorta to the supraceliac abdominal aorta-surgical option applied to reoperation for aortic coarctation or interruption. J Jpn Assoc Thorac Surg 1997;45:1690-5.

14. Jacob T, Cobanoglu A, Starr A. Late results of ascending aorta-descending aorta bypass grafts for recurrent coarctation of aorta. J Thorac Cardiovasc Surg 1988;95:782-7.

15. Vijayanagar R, Natarajan P, Eckstein PF, Bognolo DA, Toole JC. Aortic valvular insufficiency and postductal aortic coarctation in the adult: combined surgical management through median sternotomy - a new surgical approach. J Thorac Cardiovasc Surg 1980;79:266-8.

16. Barron DJ, Lamb RK, Ogilvie BC, Monro JL. Technique for extraanatomic bypass in complex aortic coarctation. Ann Thorac Surg 1996;61:241-4.

17. Powell WR, Adams PR, Cooley DA. Repair of coarctation of the aorta associated with intracardiac repair. Tex Heart Inst J 1983;10:409-13

18. Pethig K, Wahlers T, Tager S, Borst H. Perioperative complications in combined aortic valve replacement and extraanatomic ascending-descending bypass. Ann Thorac Surg 1996;61:1724-6.

19. Morris RJ, Samuels LE, Brockman SK. Total simultaneous repair of coarctation and intracardiac pathology in adult patients. Ann Thorac Surg 1998;65:1698-702.

20. Akl BF. Ascending-distal aorta bypass [letter]. Ann Thorac Surg 1985;39:196.

21. Karolczak MA, McKay R, Arnold R. Right-sided intrathoracic bypass graft for complex or recurrent coarctation of the aorta. Eur J Cardiothorac Surg 1989:3;278-81.

22. Fokin A, Orechowa L, Werbowetsky L. Aorto-aortic bypass through the right pleural cavity in recurrent coarctation of the aorta. Vasa 1992;21:422-3.

23. Caspi J, Ilbawi MN, Milo S, Bar-El Y, Roberson DA, Thilenius $\mathrm{OG}$, et al. Alternative techniques for surgical management of recoarctation. Eur J Cardiothorac Surg 1997;12:116-9.

24. Iguro Y, Yamashita M, Murata R, Fukumoto Y, Taira A. Rightsided intrathoracic bypass grafting for a coarctation of the aorta in an advanced aged woman. J Jpn Assoc Thorac Surg 1997;45:1743-6.

25. Soulen RL, Kan J, Mitchell S, White RI Jr. Evaluation of balloon angioplasty of coarctation restenosis by magnetic resonance imaging. Am J Cardiol 1987;60:343-5. 
26. DeLeon MM, DeLeon SY, Quinones JA, Roughneen PT, Magliato KE, Vitullo DA, et al. Management of arch hypoplasia after successful coarctation repair. Ann Thorac Surg 1997;63:975-80.

\section{Discussion}

Dr John J. Lamberti (New York, NY). We share the authors' enthusiasm for the selective use of this technique in patients with complex abnormalities of the transverse arch and descending aorta. In our hands, the patient has almost always had a graft in the left side of the chest before we would use the anterior approach. We prefer to make the anterior operation the last operation on the aorta if possible. Our experience spans approximately the same period as the authors', and we have very similar results.

We have usually placed the distal anastomosis below the diaphragm in the supraceliac abdominal aorta, as I think was originally described by the Texas Children's group. This does necessitate extending the sternotomy incision into the upper abdomen, dividing the linea alba, and taking down the left lobe of the liver. The authors' approach clearly has merit, and I will consider it the next time I encounter a candidate for this type of operation. In our series, patients who had previously had a graft placed for interrupted aortic arch had a small ascending aorta. I think partial bypass is useful to facilitate placement of the partial clamp in these patients lest the proximal anastomosis become kinked (which we have seen in at least 1 patient).

The median size of the grafts was $20 \mathrm{~mm}$. What would you recommend as the next operation for the smaller patients who are destined to outgrow the graft, and are you concerned that the graft will tether the aorta as these patients complete their somatic growth?

You described 4 intracardiac operations after implantation of the bypass graft. Did you encounter difficulty placing the aortic crossclamp? When you are dealing with this type of aortic arch and you know the patient has a bicuspid aortic valve, it becomes like a chess game or a billiard match, wherein you are lining up your next shot or move as you treat the problem at hand. Do you have any technical suggestions for the positioning of the graft when you know that you are likely to be coming back to operate on the aortic root?

Dr Kanter. As we mentioned, only 3 patients had an interrupted aortic arch, but in those 3 we did not have much difficulty with the proximal anastomosis because of the size of the aorta.

The next operation in the smaller children is problematic. As I pointed out, the majority of these children were in the older age group and our hopes are that this operation will be their last operation. For the next operation, I think it would be necessary to enter the left side of the chest again or to replace the graft from the front.

Does it tether? That certainly is a concern. Again, I would not apply this technique to younger children, but we do try to allow sufficient redundancy to avoid problems. During reoperations, the placement of the clamp was individualized. In fact, in 1 child I actually used the graft itself for aortic cannulation and that worked out quite well. The aorta always must be clamped proximal to the graft, but that can be difficult with extra-anatomic bypass grafts, particularly during aortic operations.

Dr Pedro J. del Nido (Boston, Mass). My question is a technical one. With this procedure, you are now doing the anastomosis anteriorly, placing that graft very close to the esophagus, if not abutted against it. The late complications of aorta-esophageal fistula, which are obviously very serious, could occur here. Do you do anything special to try to separate the esophagus from the prosthetic graft, which is rubbing against it?

Dr Kanter. I had not even thought of that complication.

Dr del Nido. It is a described complication for a thoracic aorta graft. You have described a graft that, rather than being placed through a left thoracotomy away from the esophagus, is placed through a sternotomy much closer to the esophagus. That would be my concern.

Dr Kanter. The direct answer to your question is no, we have not done anything to protect the graft from the esophagus. We ought to.

Dr Joseph J. Amato (Chicago, Ill). As the authors have indicated by this new approach, many roads lead to Rome and the aorta can be reached from alternative locations. It would seem that the aorta would naturally lie in a more anatomic position when approached through the left side of the chest. I question the hesitation to use the standard approach.

Like Dr del Nido, I worry about the proximity of the graft to the esophagus, the risk of erosion of the esophagus, and the fixed length of a graft placed in a 7-year-old who will grow to adulthood. I am concerned also that the aorta will be distorted by the graft as the child grows.

Dr Kanter. Are you asking why we do not make our approach through the left side of the chest?

Dr Amato. Yes.

Dr Kanter. The answer is, ease of access to the ascending aorta. The operation certainly can be done through the left side of the chest, but our philosophy was to avoid a second thoracotomy. Approaching the ascending aorta through the right side of the chest also allows easy access to the descending aorta. 